\title{
Primacy effects in impression formation as a function of type of impression
}

\author{
THOMAS RYWICK \\ State University of New York at Fredonia, Fredonia, N.Y. 14063
}

To determine if the different order effects in impression formation observed in studies of adjective description (primacy effects) and in a face-to-face study of interaction (recency effects) are a function of the types of impressions requested (likableness vs cooperativeness, respectively), an adjective description study was done in which $\mathrm{Ss}$ were asked to form both types of impressions. Using adjectives that were normatively equated with respect to degrees of likableness and cooperativeness, it was found that likableness impressions were governed by primacy to a significantly greater degree than cooperativeness impressions.

Investigators employing adjective descriptions of people (standard impression-formation task, or SIFT) have generally reported primacy effects in impressions of likableness (Asch, 1946; Anderson, 1965). However, in a recent experiment using a game situation which involved face-to-face interaction of two Ss, Wilson \& Insko (1968) obtained consistent recency effects in impressions of the cooperativeness of the other person. Wilson and Insko explained that their finding of recency may be due to the "face-to-face interaction per se" or the "game setting per se." Precise specification of possible influential variables was not made, however. Although many specific differences exist between the SIFT and Wilson and Insko experimental situations, one difference immediately recognizable is the type of impression asked of Ss. Whereas impressions of likableness were obtained in the SIFT, impressions of cooperativeness, a trait that is probably considered less often than likableness in our daily perceptions of people, were obtained by Wilson and Insko. Possibly, people have more practice in forming likableness impressions. They may therefore be able to incorporate immediately into their impressions each piece of likableness information as it is presented. Other impressions, such as of cooperativeness, may have to be formed after all the information is processed, with subsequently less weight given to earlier information due to forgetting.

The purpose of the present study was to determine if order effects vary with different types of impressions. \section{SUBJECTS}

Fifty female and thirty male undergraduates in introductory psychology courses at the State University of New York at Fredonia served as Ss. All Ss volunteered to take part in the experiment which was carried out during portions of four

\section{class periods.}

EXPERIMENTAL MANIPULATIONS

A SIFT situation, with modifications to allow the manipulation of variables, was employed. The independent variables were (1) list replication (two different lists of adjective sets were created and incorporated in the design), (2) order of ratings (half of the Ss made likableness ratings and then cooperativeness ratings, while the remaining $S s$ made the ratings in reverse order), (3) set size (half the adjective sets contained four adjectives and half contained eight adjectives), and (4) type of impression (Ss were instructed to form impressions of both the likableness and cooperativeness of the described persons). Although significant effects of the first three variables were not anticipated, they were included to allow some limited conclusions concerning the generalizability of the results.

\section{MATERIALS}

Each $\mathrm{S}$ was presented with one of two lists, each list containing 32 sets of adjectives. Sixteen sets in each list were buffer sets, consisting of adjectives presented in random order. The remaining 16 sets were ordered sets with either positive adjectives followed by negative ( $P-N$ sets) or negative followed by positive (N-P sets). There were 4 P.N and 4 N-P sets of each size (4 vs 8 ) in each list.

Since a direct comparison of ratings of likableness and cooperativeness was to be made, it was necessary to pretest individual adjectives to insure that they elicited equivalent ratings of likableness and cooperativeness. Two hundred and fifteen Ss were therefore asked to rate 300 adjectives selected from Anderson's (1968) list on 7-point scales ( 1 to 7 ) of likableness and cooperativeness. Fifty adjectives with mean ratings of 5.98 on both scales and 50 adjectives with mean ratings of 0.95 on the likableness scale and 0.87 on the cooperativeness scale were selected as the positive and negative adjectives, respectively. The standard deviations of the mean likableness and cooperativeness ratings of the 50 positive adjectives were 0.392 and 0.407 , respectively. The respective standard deviations of the negative adjectives were 0.413 and 0.335 .

The ordered adjective sets used in the present experiment were created by selecting adjectives randomly from the 100 selected above. Selection was done with replacement, although repetition of an adjective within a set was not permitted. Buffer sets were created by selecting adjectives randomly from Anderson's entire list. The two lists of adjective sets were each recorded onto tape twice (once with the positive and negative halves of the ordered sets reversed). Three precautions were tkaen to avoid bias in the recordings. First, the reader was kept naive as to the purpose of the study. Second, the reader actually read sets of 6 and 10 adjectives where the first and last adjectives of each set were arbitrarily added by $\mathrm{E}$. However, only the middle 4 or 8 adjectives were actually recorded. This procedure eliminated any differences in enunciation given to the first and last adjectives of a set. Third, four P-N and four N-P sets from each recorded list were selected randomly and presented to 30 judges who were asked to decide which half of each set had the advantage with respect to loudness, forcefulness, emphasis, and clarity of enunciation (the order of presentation of the halves of each set was counterbalanced). Using this forced-choice procedure, it was found that none of the tested sets showed systematic bias with respect to loudness, etc.

\section{PROCEDURE}

Twenty Ss (12 females and 8 males or 13 females and 7 males) were assigned randomly to each Order of Rating by List of Replication condition. Twenty Ss were run together and received one of the two recordings of one of the lists. Ss were given rating booklets containing 32 pairs of rating scales. For half the Ss present, the first scale of each pair was the likableness scale. The scales were reversed for the remaining $S$ s.

The Ss were told that the purpose of the experiment was to study how people form impressions of other people from limited amounts of information about those people. Ss were told that the information was in the form of sets of either four or eight adjectives. Although the different size sets were distributed randomly in the list, Ss were quickly aware of which sets were of four adjectives, since an unusually long delay would follow the fourth adjective (adjectives were recorded at a constant rate of one 
Table 1

Mean Rating Sums

\begin{tabular}{|c|c|c|c|c|}
\hline \multirow{3}{*}{$\begin{array}{c}\text { Rating } \\
\text { Order }\end{array}$} & \multicolumn{4}{|c|}{ Type of Impression } \\
\hline & \multicolumn{2}{|c|}{ Cooperativeness } & \multicolumn{2}{|c|}{ Likeableness } \\
\hline & L-C & C-L & $\mathrm{L}-\mathrm{C}$ & C-L \\
\hline \multicolumn{5}{|l|}{ P-N Sets } \\
\hline $\begin{array}{l}\text { Mean } \\
\text { SD }\end{array}$ & $\begin{array}{r}14.64 \\
3.58\end{array}$ & $\begin{array}{r}15.64 \\
3.78\end{array}$ & $\begin{array}{r}16.02 \\
4.01\end{array}$ & $\begin{array}{r}16.56 \\
3.90\end{array}$ \\
\hline \multicolumn{5}{|l|}{ N-P Sets } \\
\hline Mean & 15.37 & 14.60 & 14.21 & 14.44 \\
\hline $\begin{array}{c}\text { SD } \\
\text { Difference }\end{array}$ & 3.78 & 3.60 & 3.62 & 3.65 \\
\hline Mean & -0.73 & 1.04 & 1.81 & 2.12 \\
\hline SD & 4.16 & 4.06 & 4.03 & 4.67 \\
\hline
\end{tabular}

Note-Since higher ratings indicate greater degrees of likeableness or cooperativeness. positive difference scores represent primacy and negative scores represent recency.

every $2 \mathrm{sec}$ ). Ss were instructed on the use of the rating scales which were 7-point scales anchored at the ends with the words "likable" and "unlikable" or "cooperative" and "uncooperative." Ss were given $16 \mathrm{sec}$ after each set in which to make the two ratings.

\section{RESULTS AND DISCUSSION}

A $2^{4}$ analysis of variance with repeated measures on the factors of set size and type of impression was used to analyze the difference scores calculated by subtracting the sum of an S's ratings to four N-P sets from his ratings to four $\mathrm{P}-\mathrm{N}$ sets of the same size. Means and standard deviations of these rating sums as well as of the difference scores appear in Table 1, collapsed across list replication and set size.

The main effects of list replication $(F<1)$, order of rating $(F=2.323$, $\mathrm{df}=1 / 76, \quad \mathrm{p}<.25)$, and set size $(F<1)$ were not significant. The only interaction which approached significance was the Order of Rating by Type of Impression interaction $(\mathrm{F}=3.849, \mathrm{df}=1 / 76, \mathrm{p}<.07)$.

The only significant effect was type of impression ( $\mathrm{F}=24.340, \mathrm{df}=1 / 76$, $\mathrm{p}<.001)$. The mean difference scores for likableness and cooperativeness ratings were 1.96 and 0.16 , respectively. The data are therefore in line with previous findings of SIFT studies, which have resulted in primacy effects. Although the present data indicate that the degree of primacy is less with cooperativeness ratings, the recency effects obtained by Wilson and Insko were not replicated. Most likely, other factors, which differentiate the SIFT and Wilson and Insko studies are also effective in reducing primacy or facilitating recency.

This study demonstrated that differential order effects can be obtained with different types of impressions. A possible explanation for this finding, presented earlier, is based on the assumption that people have more practice in forming likableness impressions and are therefore able to utilize information in their impression as soon as it is presented, while. cooperativeness impressions must be formed after all the information is presented with subsequently less reliance on earlier information due to forgetting. Future research, perhaps utilizing a face-to-face interaction situation as well as SIFT situations and with Ss forming a variety of impressions, would be useful in investigating the efficacy of this explanation as well as in determining the external validity of the present findings.

\section{REFERENCES}

ANDERSON, N. $H$. Primacy effects in impression formation using a generalized order effects paradigm. Joumal of Personality \& Social Psychology, 1965, 2, 1-9.

ANDERSON, N. H. Likableness ratings of 555 personality-trait words. Joumal of Personality \& Social Psychology, 1968, 9 . 272-279.

ASCH, S. E. Forming impressions of personality. Joumal of Abnormal \& Social Psychology, 1946, 41, 258-290.

WILSON, W., \& INSKO, C. Recency effects in face-to-face interaction. Joumal of Personality \& Social Psychology, 1968, 9, 21-23. 